\title{
Tetrahydrofuran (co)polymers as Potential Materials for Vascular Prostheses
}

\author{
B. J. M. Pol, L. van der Does \& A. Bantjes \\ Department of Chemical Technology, Biomaterials Section, University of Twente, PO Box 217, 7500 AE Enschede, \\ The Netherlands
}

\begin{abstract}
Polyethers were studied as potential materials for vascular prostheses. By crosslinking poly(tetramethylene oxide) (PTMO) with poly(ethylene oxide) (PEO), hydrophilic networks were obtained containing PTMO as well as PEO. Attempts were made to reduce the crystallinity and melting point of PTMO because of the required elastomeric behaviour at body temperature. Compared to non-crosslinked PTMO, crosslinking in the melt resulted in a decrease in the melting point from 43.7 to $38.4{ }^{\circ} \mathrm{C}$ and a decrease of the crystallinity from 46 to $28 \%$. By copolymerizing tetrahydrofuran with oxetane or dimethyloxetane, melting points below $38^{\circ} \mathrm{C}$ were obtained, together with crystallinities lower than $20 \%$.
\end{abstract}

\section{INTRODUCTION}

For the application of polymers for vascular prostheses, hydrophilicity and elastomeric behaviour at body temperature are important parameters. From reports of studies on copolyetherurethanes, ${ }^{1}$ Bots et $a l^{2}$ derived the hypothesis that polyethers might be promising materials. Poly(ethylene oxide) (PEO) was chosen as the biocompatible, hydrophilic component, and atactic poly(propylene oxide) (PPOx) as the more hydrophobic and mechanically stronger one. Crosslinked blends of PEO and PPOx (ratio : 10/90) appeared hydrophilic and very blood-compatible. In vitro, low protein adsorption, platelet adhesion and kallikrein generation was found, as well as a high APTT value. In vivo, in the abdominal aorta of rats, no thrombus formation could be detected during the 6 weeks after implantation and furthermore, a thin neointima of smooth muscle cells, lined by an endothelial lining on the surface of the grafts, was found. However, the implantation experiments also showed that the polyether grafts had a limited dimensional stability, which was probably due to thermo-oxidative degradation of PPOx; PPOx contains tertiary hydrogen atoms in the main chain, which are sensitive to oxidation.
This paper reports investigations of homo- and copolymers of tetramethylene oxide as part of our study of the applicability of polyethers for vascular prostheses. Poly(tetramethylene oxide) (PTMO) was studied because this polymer has no tertiary hydrogen atoms in the main chain and will probably be less susceptible to thermooxidative attack. From preliminary experiments it could be concluded that UV treatment of mixtures of PTMO and PEO and a crosslinking agent, dicumyl peroxide (DCP), had resulted in the formation of polymer networks, differing in hydrophilicity and containing PTMO as well as PEO.

However, PTMO is semi-crystalline with a melting point higher than $37^{\circ} \mathrm{C}$. Crystallinity not only leads to non-elastomeric behaviour, but semi-crystalline polymers have also been reported to be more reactive than their non-crystalline counterparts with respect to platelet activation. ${ }^{3}$

In this study, attempts were made to decrease the crystallinity and the melting point by crosslinking of PTMO at various temperatures and by copolymerization of tetrahydrofuran with oxetane (OX) or dimethyloxetane (DMOX). 


\section{EXPERIMENTAL}

\section{Materials}

Monomers and solvents

- Tetrahydrofuran (THF) (Merck) was refluxed over and distilled from sodium wire prior to use.

- Dimethyloxetane (DMOX) was prepared by addition of a 2,2-dimethyl-1,3-propanediol (Merck) solution in $\mathrm{H}_{2} \mathrm{SO}_{4}$ to a boiling aqueous $\mathrm{NaOH}$ solution, according to the method of Shmoyer and Case. ${ }^{4}$

-DMOX and Oxetane (OX) (Fluka) were refluxed over and distilled from $\mathrm{KOH}$ prior to use.

- Toluene (Merck) and dichloromethane (Merck) were used as received.

-Dicumyl peroxide (DCP) (Merck), recrystallized twice from methanol, was used as the crosslinking agent.

- $\mathrm{SbCl}_{5}$ (Aldrich; $1.0 \mathrm{M}$ solution in $\mathrm{CH}_{2} \mathrm{Cl}_{2}$ ) was used as received.

- $\mathrm{Al}(i-\mathrm{Bu})_{3}-0 \cdot 5 \mathrm{H}_{2} \mathrm{O}$ complex was prepared from $\mathrm{Al}(i-\mathrm{Bu})_{3}$ (Aldrich; $1.0 \mathrm{M}$ solution in toluene) by the addition of water at $0{ }^{\circ} \mathrm{C}$.

\section{Polymers}

- High molecular weight PEO $\left(\bar{M}_{\mathrm{w}}=6 \times 10^{5}\right.$ and $5 \times 10^{6} \mathrm{~g} / \mathrm{mol}$ ) was purchased from BDH Chemicals and Aldrich, respectively.

- High molecular weight PTMO $\left(T_{\mathrm{m}}=43.7^{\circ} \mathrm{C}\right.$, $X_{\mathrm{c}}=46 \%, \quad \bar{M}_{\mathrm{n}}=1.9 \times 10^{5} \mathrm{~g} / \mathrm{mol} ; \quad \bar{M}_{\mathrm{w}}=4.5$ $\times 10^{5} \mathrm{~g} / \mathrm{mol} ; \eta_{\text {inh }}$ (inherent viscosity) $=2.8 \mathrm{dl} / \mathrm{g}$ $(0.25 \%$ in toluene) $)$ was synthesized by bulk polymerization of THF with $\mathrm{SbCl}_{5}$ as catalyst.

-Poly(THF-co-OX $) \quad\left(\eta_{\text {inh }}=1.8 \mathrm{dl} / \mathrm{g} \quad(0.25 \%\right.$ in toluene) $)$ and poly(THF-co-DMOX) $\left(\eta_{\text {inh }}=2 \cdot 2\right.$ $\mathrm{d} 1 / \mathrm{g}(0 \cdot 25 \%$ in toluene) were prepared by bulk copolymerization of THF/OX and THF/DMOX mixtures respectively with $\mathrm{Al}(i-\mathrm{Bu})_{3}-0 \cdot 5 \mathrm{H}_{2} \mathrm{O}$ complex as catalyst.

\section{METHODS}

\section{Film preparation}

Polymers or mixtures of polymers and DCP (always 2 parts DCP per hundred parts total polymer) were dissolved in $\mathrm{CH}_{2} \mathrm{Cl}_{2}$ and films were cast from viscous $5 \%(\mathrm{w} / \mathrm{v})$ solutions, followed by evaporation of the solvent under a hood overnight.

Crosslinking was induced by UV-irradiation $(2 \mathrm{~h}$ per side) at a distance of $10 \mathrm{~cm}$ from a Hanau
Lamp TQ81 (wave length: $254 \mathrm{~nm}$ ) in a nitrogen atmosphere.

\section{Film characterization}

\section{Swelling behaviour}

Irradiated films were swollen in water or toluene for $48 \mathrm{~h}$, in which equilibrium swelling was reached, followed by drying the films to constant weight. The swelling is given by the weight ratio of the swollen and the dried films $\left(W_{\text {wet }} / W_{\text {dry }}\right)$.

\section{$D S C$ analysis}

The thermal properties of the films were studied using a Perkin-Elmer DSC 7 Differential Scanning Calorimeter. Crystallinities $\left(X_{\mathrm{c}}\right)$ were calculated from the heats of fusion using a value of $167 \mathrm{~J} / \mathrm{g}$ for the enthalpy of melting for PTMO. ${ }^{6}$

Indium and gallium were used to calibrate the temperature scale and to determine the heat of fusion.

Before heating, the samples were cooled to $0^{\circ} \mathrm{C}$ and kept there for $5 \mathrm{~min}$.

\section{RESUCTS AND DISCUSSION}

\section{Characterization of crosslinked PTMO/PEO blends}

Blends of PTMO/PEO/DCP were crosslinked by

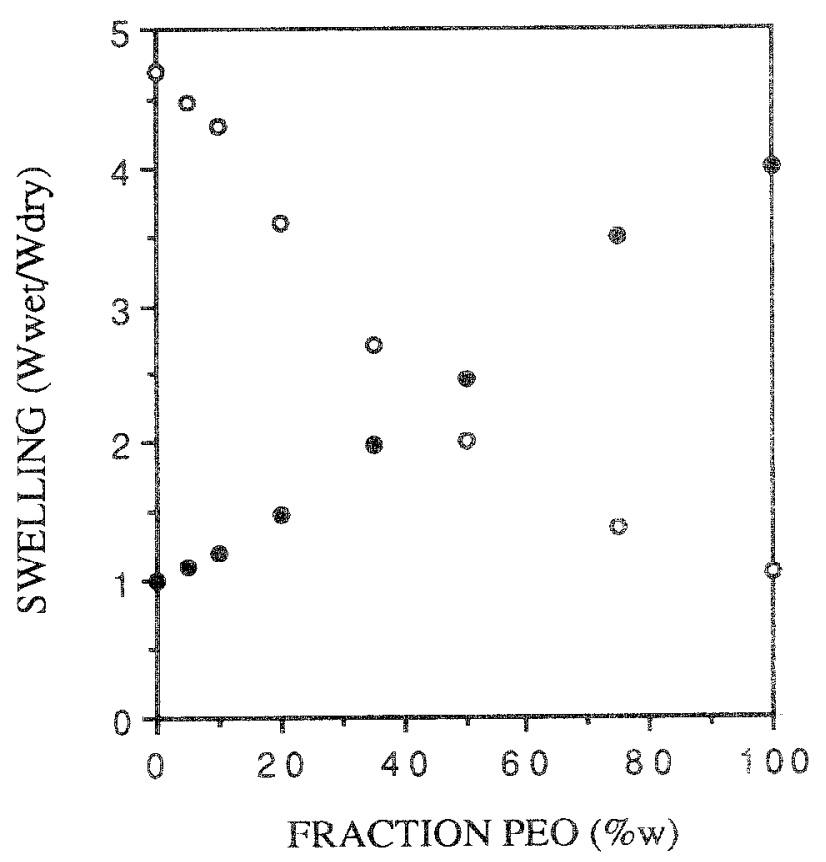

Fig. 1. Swelling of crosslinked PTMO/PEO/DCP blends as a function of the PEO weight fraction $(O=i n$ water; $O=i n$ toluene). 


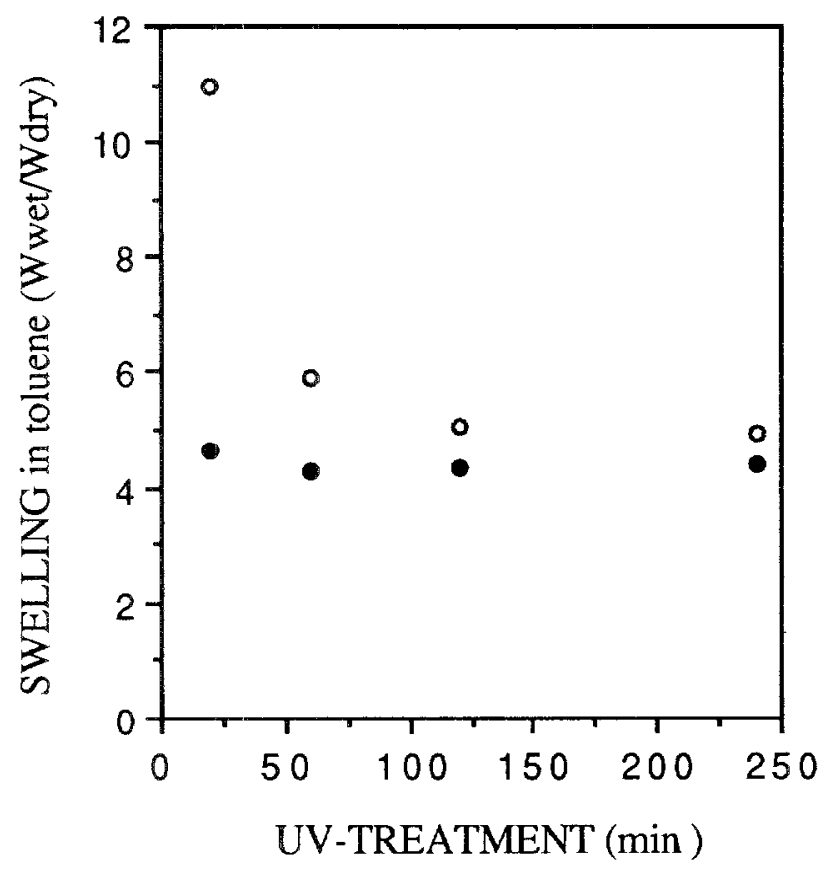

Fig. 2. Swelling in toluene of PTMO/DCP films (100/2) crosslinked with UV at $20^{\circ} \mathrm{C}(\bigcirc)$ and at $60^{\circ} \mathrm{C}$

UV treatment and the swelling in water (solvent for PEO, non-solvent for PTMO) and in toluene (solvent for PTMO, non-solvent for PEO) was determined (Fig. 1). Because swelling in water as well as in toluene was observed, it could be concluded that in the networks both PTMO and PEO were incorporated.

Although further characterization of the crosslinked systems was not studied extensively, DSC measurements indicated phase separation of PTMO and PEO.
Table 1. Melting points $T_{\mathrm{m}}$ and crystallinities $X_{\mathrm{C}}$ (recorded at a heating rate of $2^{\circ} \mathrm{C} / \mathrm{min}$ ). Films were kept at room temperature for 7 weeks after heating to $80^{\circ} \mathrm{C}$

\begin{tabular}{lcc}
\hline & $T_{\mathrm{m}}\left({ }^{\circ} \mathrm{C}\right)$ & $X_{\mathrm{c}}(\%)$ \\
\hline PTMO/DCP (not crosslinked) & $43 \cdot 7$ & 46 \\
PTMO/DCP (crosslinked at $\left.20^{\circ} \mathrm{C}\right)$ & $41 \cdot 0$ & 37 \\
PTMO/DCP (crosslinked at $\left.60^{\circ} \mathrm{C}\right)$ & 38.4 & 28 \\
\hline
\end{tabular}

\section{Crosslinking of PTMO at various temperatures}

\section{Effect on crosslinking density}

Crosslinking of PTMO in the melt phase $\left(60^{\circ} \mathrm{C}\right)$ occurred much faster than at $20^{\circ} \mathrm{C}$ with the semi-crystalline PTMO (Fig. 2). Furthermore, crosslinking at $60^{\circ} \mathrm{C}$ led to a somewhat higher crosslinking density. These results are in agreement with reports from Chen and Rånby ${ }^{7}$ that crosslinking of (semi-crystalline) poly(ethylene) (PE) above $T_{\mathrm{m}}$ leads to a higher crosslinking density than crosslinking in the solid state.

\section{Effect on $T_{\mathrm{m}} /$ crystallinity}

PTMO/DCP films, non-crosslinked, crosslinked by UV treatment at $20^{\circ} \mathrm{C}$ and $60^{\circ} \mathrm{C}$, respectively, were heated to $80^{\circ} \mathrm{C}$ to allow complete melting. They were subsequently kept at $20^{\circ} \mathrm{C}$ for 7 weeks because of the possibility of a time-dependent secondary crystallization of PTMO, leading to an increase of $T_{\mathrm{m}}$ and the crystallinity. ${ }^{8,9}$ Table 1 shows the results of the DSC analysis of the films and it is obvious that crosslinking in the solid state $\left(20^{\circ} \mathrm{C}\right)$

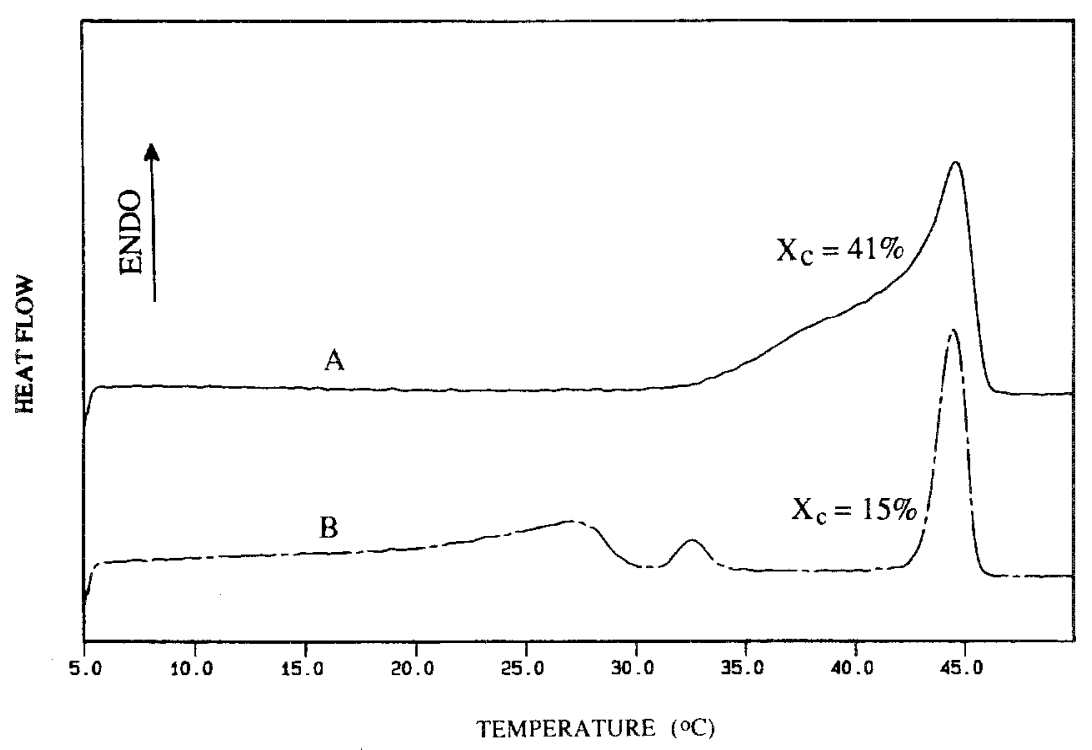

Fig. 3. DSC curves of PTMO/DCP films (100/2) crosslinked at $20^{\circ} \mathrm{C}$, measured at $20^{\circ} \mathrm{C}(\mathrm{A})$ and at $37^{\circ} \mathrm{C}(\mathrm{B})$ (heating rate: $\left.2^{\circ} \mathrm{C} / \mathrm{min}\right)$. 
Table 2. Effect of copolymerizations of THF with OX or DMOX on $T_{\mathrm{m}}$ and $X_{c}$

\begin{tabular}{lcc}
\hline & $\begin{array}{c}\text { Poly }(\text { THF-co-OX) } \\
\text { (mole fractions) }\end{array}$ & $\begin{array}{c}\text { Poly(THF-co-DMOX) } \\
\text { (mole fractions) }\end{array}$ \\
\hline $\begin{array}{l}\text { Monomeric unit } \\
-\mathrm{CH}_{2}-\mathrm{CH}_{2}-\mathrm{CH}_{2}-\mathrm{CH}_{2}-\mathrm{O}\end{array}$ & 0.908 & \\
$-\mathrm{CH}_{2}-\mathrm{CH}_{2}-\mathrm{CH}_{2}-\mathrm{O}-$ & 0.092 & 0.936 \\
$-\mathrm{CH}_{2}-\mathrm{C}\left(\mathrm{CH}_{3}\right)_{2}-\mathrm{CH}_{2}-\mathrm{O}-$ & & 0.064 \\
$T_{\mathrm{m}}\left({ }^{\circ} \mathrm{C}\right)$ & $33 \cdot 7$ & $33 \cdot 8$ \\
$X_{\mathrm{c}}(\%)$ & 13 & 17 \\
\hline
\end{tabular}

leads to a decrease of $T_{\mathrm{m}}$ and the crystallinity. Crosslinking at $60^{\circ} \mathrm{C}$ resulted in a further decrease of both the $T_{\mathrm{m}}$ and the crystallinity, clearly indicating the effect of a decreased order in the melt phase.

Compared to the results of Chen and Rånby ${ }^{10}$ and of Dijkstra et al. ${ }^{11}$ regarding the effect of crosslinking of PE in the melt on $T_{\mathrm{m}}$ and the crystallinity, the decrease of $T_{\mathrm{m}}$ for PTMO is less pronounced. Increasing the amount of DCP will increase the crosslinking density and might lead to larger melting point depressions, but will probably have a negative effect on the mechanical properties of PTMO, such as tear strength and elongation at break.

It should be noted, on the other hand, that Table 1 gives DSC data from measurements at $20^{\circ} \mathrm{C}$. The degree of crystallinity of crosslinked PTMO was found to be significantly lower at $37^{\circ} \mathrm{C}$, as can be seen from Fig. 3 (films crosslinked at $20^{\circ} \mathrm{C}$, but not heated to $80^{\circ} \mathrm{C}$ ).

\section{Copolymerization}

THF was copolymerized to investigate the effect of comonomers on $T_{\mathrm{m}}$ and $X_{\mathrm{c}}$, because insertion of other monomeric units in the polymeric chains will disturb the regularity. Oxetane (OX) and dimethyloxetane (DMOX) were chosen because polymers will be obtained without tertiary hydrogen atoms in the main chain. In Table 2 the composition of the copolymers is given together with data for $T_{\mathrm{m}}$ and $X_{\mathrm{c}}$.

The results show that copolymerization is much more effective in decreasing $T_{\mathrm{m}}$ and $X_{\mathrm{c}}$ than crosslinking of PTMO (Table 1).

These copolymers are interesting as materials for vascular prostheses because they show elastomeric behaviour at $37^{\circ} \mathrm{C}$. Therefore, research on the crosslinking of these copolymers with PEO is planned for the future.

\section{CONCLUDING REMARKS}

Although a certain decrease of crystallinity and melting point depression of PTMO was achieved by crosslinking in the melt, further research is necessary for a reliable evaluation of PTMO as a potential material for vascular grafts. By copolymerization of tetrahydrofuran with oxetane or dimethyloxetane, the crystallinity and melting point could be reduced significantly, and therefore copolymerizations are being studied in more detail.

\section{REFERENCES}

1. Sa Da Costa, V., Study of polyurethanes for biomaterials. PhD thesis, Massachusetts Institute of Technology, Cambridge, USA, 1979.

2. Bots, J. G., van der Does, L., Bantjes, A., Small diameter blood vessel prostheses from blends of polv(ethylene oxide) and poly(propylene oxide). Biomaterials, 7 (1986) $393-9$

3. White, R. A., Vascular prostheses: Present status and future development. In Blood Compatibility $H$, ed. D. F. Williams. CRC Press, Boca Raton, Florida, 1987 p. 50.

4. Shmoyer, L. F. \& Case, L. C., A new method for the syn thesis of cydlic ethers. Nature, 187 (1960) 592-3.

5. Vandenberg, E. J., Epoxide polymers: Synthesis, stereor chemistry, structure, and mechanism. $I$. Polym. Sol. Part A-1, 7 (1969) 525-67.

6. Kretz, M., Meurer, B., Lotz, B., Weill, G., Plastic deformation of poly tetramethylene oxide). I. Inffuence of molecular weight distribution, crystallinity, and structure. $J$ Polym. Sci. Polym. Phys. Ed., 26 (1988) 663-75.

7. Chen, Y. L. \& Rånby, B., Photocrosslinking of poly(ethylene). I. Photoinitiators, crosslinking agent and reaction kinetics. J. Polym. Sci. Polym. Chem. Ed., 27 (1989) $4051-75$

8. Wamer, F. P., Brown, D. S. \& Wetton, R. E., Secondary crystallization of poly(tetramethylene oxide). 7 . Chem. Soc. Faraday Trans. 1, 72 (1976) 1064-77

9. Wamer, F. P. Brown, D. S. \& Wetton, R, E. Inter-iamellar crystallization in poly(tetramethylene oxide). Polymer, 22 (1981) $1349-52$.

10. Chen, Y. L. \& Rånby, B., Photocrosslinking of poly(cthy. lene). II. Properties of photocrosslinked poly(ethylene). I. Polym. Sci. Polym. Chem. Ed., 27 (1989) 4077-86.

11. Dijkstra, D. J., Hoogsteen, W. \& Pennings, A. J., Cross-linking of ultra-high molecular weight polv(ethylene) by means of electron beam irradiation. Polymer, 30 (1989) 866-73. 